\title{
Growth and development, and auxin polar transport of transgenic Arabidopsis under simulated microgravity conditions on a three-dimensional clinostat
}

\author{
Toru Shimazu ${ }^{\S}$, Kensuke Miyamoto and Junichi Ueda
}

College of Integrated Arts and Sciences, Osaka Prefecture University, 1-1 Gakuen-cho, Sakai, Osaka 599-8531, Japan

\begin{abstract}
Growth and development, and auxin polar transport in Arabidopsis thaliana transformed with $i a a H$ gene were studied under simulated microgravity conditions on a three-dimensional (3-D) clinostat. Simulated microgravity conditions on a 3-D clinostat did not affect the number of rosette leaves but promoted the growth and development (fresh weight of plant and the elongation of flower stalk) of transformants. Final growth of transformants under simulated microgravity conditions on a 3-D clinostat was almost equivalent to that grown on $1 \mathrm{~g}$ conditions in the presence of $1 \mu \mathrm{M}$ IAM (indole-3-acetamide). The activities of auxin polar transport in the segments of flower stalk (inflorescence axis) of transformants grown on $1 \mathrm{~g}$ conditions were significantly promoted by the addition of IAM. Interestingly, simulated microgravity conditions on a 3-D clinostat also promoted the activities of auxin polar transport of transformants grown on the medium with or without IAM. Based on the results in this study, transgenic plants may not have an efficient homeostatic mechanism for the control of growth and development, and auxin polar transport activity in microgravity conditions in space.
\end{abstract}

\section{Introduction}

Plant hormone, auxin (indole-3-acetic acid) has been recognized to play an important role in plant growth and development through the mode of actions of its polar transport on the earth. We have studied plant growth and development, and auxin polar transport under simulated microgravity conditions on a 3-dimensional (3-D) clinostat. A series of our studies using a 3-D clinostat showed that auxin polar transport in flower stalk of Arabidopsis thaliana Columbia ecotype was substantially affected by a long duration under simulated microgravity conditions on a 3D clinostat, but not affected by a short duration (Oka et al. 1995, Ueda et al. 1996, 1997, 1999).

Higher plants have been considered to mainly biosynthesize indole-acetic acid (IAA) from tryptophan via indole-3-pyruvic acid and indole-3-acetaldehyde. Those infected with Pseudomonas (Kosuge et al. 1966, Morris 1986), Agrobacterium (Thomashow et al. 1984, Van Onckelen et al. 1985, Kemper et al. 1985) or Bradyrhizobium (Sekine et al. 1988), however, have been found to biosynthesize IAA via indole-3-acetamide (IAM) of the product catalyzed by tryptophan monooxygenase (Fig. 1). Although IAM has substantially been detected in higher plants (Kawaguchi et al. 1993), biosynthetic pathway of IAA via IAM in higher plants has not been

\section{Original paper}

Received October 8, 2003

Accepted December 1, 2003

Address for correspondence: Junichi Ueda College of Integrated Arts and Sciences,

Osaka Prefecture University, 1-1 Gakuen-cho, Sakai,

Osaka 599-8531, Japan

E-mail: ueda@el.cias.osakafu-u.ac.jp

$\S$ Present address:

Japan Space Forum, 1-29-6 Hamamatsu-cho,

Minato-ku, Tokyo 105-0013, Japan confirmed yet. It seems, therefore, that the biosynthetic pathway of IAA via IAM is independent from the native biosynthetic pathway of IAA in higher plants. The endogenous level of free IAA in tobacco callus which was transformed using Ti plasmid with iaaM gene and indoleacetamide hydrolase ( $\mathrm{iaHH}$ ) gene was double of nontransformed one (Sitbon et al. 1991).

In order to know the mechanism of gravity on the regulation of plant growth and development in relation to auxin polar transport, the introduction of transgenic plants was intended. Arabidopsis thaliana Columbia ecotype transformed with $i a a H$ gene was used, in which the endogenous auxin level will be expected to be high by biosynthesizing from indole-3-acetamide as a substrate. The purpose of the present study is to know the effects of a simulated microgravity conditions on a 3-D clinostat on the growth and development, and auxin polar transport in transgenic Arabidopsis. A possibility introducing transgenic plants as cultivating plants in microgravity conditions in space will also be discussed.

\section{Materials and Methods}

\section{Plant materials}

Transgenic Arabidopsis with iaaH gene referred to as R12 was constructed by the same method reported previously (Oka et al. 1999). Wild type of the transgenic plants was Columbia ecotype. Seeds of wild type and transgenic one were sterilized by immersing in a $70 \%(\mathrm{v} /$ v) ethanol for 1 minute and a solution of $10 \%(\mathrm{v} / \mathrm{v})$ liquid bleach (Haitar, Kao Co., Ltd., Japan) for 10 minutes, followed by extensive washing with sterilized water. Seeds were sowed on $2 \%$ agar, then kept at $4{ }^{\circ} \mathrm{C}$ for 4 days. After that, they were germinated at $25{ }^{\circ} \mathrm{C}$ in the light. The seedlings were transplanted to pots (TECHNOPOT, Sumitomo Bakelite Co., Ltd., Japan) with the Arabidopsis basic medium $\left(5 \mathrm{mM} \mathrm{KNO}_{3}, 2 \mathrm{mM} \mathrm{MgSO}_{4}, 2 \mathrm{mM}\right.$ 
$\mathrm{Ca}\left(\mathrm{NO}_{3}\right)_{2}, 2.5 \mathrm{mM} \mathrm{KH}_{2} \mathrm{PO}_{4}, 50 \mu \mathrm{M}$ Fe-EDTA, $70 \mu \mathrm{M}$ $\mathrm{H}_{3} \mathrm{BO}_{3}, 14 \mu \mathrm{M} \mathrm{MnCl}_{2}, 0.5 \mu \mathrm{M} \mathrm{CuSO}_{4}, 1 \mu \mathrm{M} \mathrm{ZnSO}_{4}, 0.2$ $\mu \mathrm{M} \mathrm{NaMoO}_{4}, 10 \mu \mathrm{M} \mathrm{NaCl}$ and $0.01 \mu \mathrm{M} \mathrm{CoCl}_{2}$ ) with $1 \%$ agar in the presence or absence of appropriate concentrations of IAM. Plants were grown under continuous white fluorescent light $\left(8 \mathrm{~W} / \mathrm{m}^{2}\right)$ at $25^{\circ} \mathrm{C}$ under $1 \mathrm{~g}$ conditions or under simulated microgravity conditions on a 3-D clinostat for 30 days.

\section{Extraction of DNA}

Ten mg leaves of plants which have Kanamycin resistant were minced in $100 \mu \mathrm{l}$ of DNA extraction buffer (0.14 M sorbitol, 0.22 M Tris-HCl (pH 8.0), 0.022 M EDTA, $0.8 \mathrm{M} \mathrm{NaCl}, 0.8 \%(\mathrm{w} / \mathrm{v})$ hexadecyltrimethylammonium bromide, $1 \%(\mathrm{w} / \mathrm{v}) \mathrm{N}$-lauroylsarcosine) with sea sand. A hundred $\mu \mathrm{l}$ of chloroform was added to this solution, mixing strongly using a mechanical vibrator. Then they were kept for 30 minutes at $65{ }^{\circ} \mathrm{C}$. They were centrifuged at 12,000 rpm for 5 minutes and their supernatant was transferred to a new tube. A hundred $\mu \mathrm{l}$ of isopropanol was added to the solution, then kept for 20 minutes at $4{ }^{\circ} \mathrm{C}$. They were centrifuged at 15,000 rpm for 10 minutes, then the pellet obtained was washed with $70 \%(\mathrm{v} / \mathrm{v})$ ethanol and dried under reduced pressure conditions.

PCR amplification

A $50 \mathrm{ng}$ of DNA extracted from the plants was used as a template for PCR. We used a PCR solution of $2 \mu \mathrm{M}$ primer including mixture of $10 \mathrm{mM}$ Tris- $\mathrm{HCl}(\mathrm{pH} \mathrm{8.3),50} \mathrm{mM}$ $\mathrm{KCl}, 1.5 \mathrm{mM} \mathrm{MgCl}_{2}, 800 \mu \mathrm{M}$ dATP • dCTP • dGTP • dTTP. We used a primer from a sequence of iaaHF1 gene (5'GTTTGAAGTAGTTGCGATAG-3') and of iaaHR1 gene (5'-GCATGAGTTATCGTTTGGAA-3'). PCR reactions included a denaturing step at $94{ }^{\circ} \mathrm{C}$ for 10 minutes followed by 30 cycles at $94{ }^{\circ} \mathrm{C}$ for 1 minute, at $55^{\circ} \mathrm{C}$ for 1 minute and at $72{ }^{\circ} \mathrm{C}$ for 2 minutes with a final extension cycle at $72{ }^{\circ} \mathrm{C}$ for 7 minutes. We used a MiniCycler ${ }^{\mathrm{TM}}$ (PTC-150, MJ Research, Inc., USA) for the PCR amplification.

\section{Analysis of auxin polar transport}

Activities of auxin polar transport in the segment of flower stalk of Arabidopsis R12 transformants were determined using the method previously reported (Oka et al. 1995). Fifty $\mu$ l of $1 \%\left[{ }^{14} \mathrm{C}\right]$ indole-3-acetic acid (American Radiolabeled Chemical Inc., USA) at the concentration of $1 \mathrm{mCi} / \mathrm{ml}$ were applied in a $1.5 \mathrm{ml}$ Eppendorf tube. Segments ( $30 \mathrm{~mm}$ in length) were prepared from flower stalks of the seedlings to be applied the radioactive auxin from the upper or the basal side of the segments. These tubes were incubated in the dark for 22 hours at $25^{\circ} \mathrm{C}$. After the incubation, 5-mm pieces of the opposite side from the donor side were excised, and their radioactivities were directly measured by a liquid scintillation counter to determine auxin polar transport.

\section{Simulated microgravity conditions}

Simulated microgravity conditions were made by a 3D clinostat with 2 axes which was designed by Professor Masamichi Yamashita, Japan Aerospace Exploration Agency (former Institute of Space and Astronautical Science). The 3-D clinostat (Model CS-2, Nihonikakikai

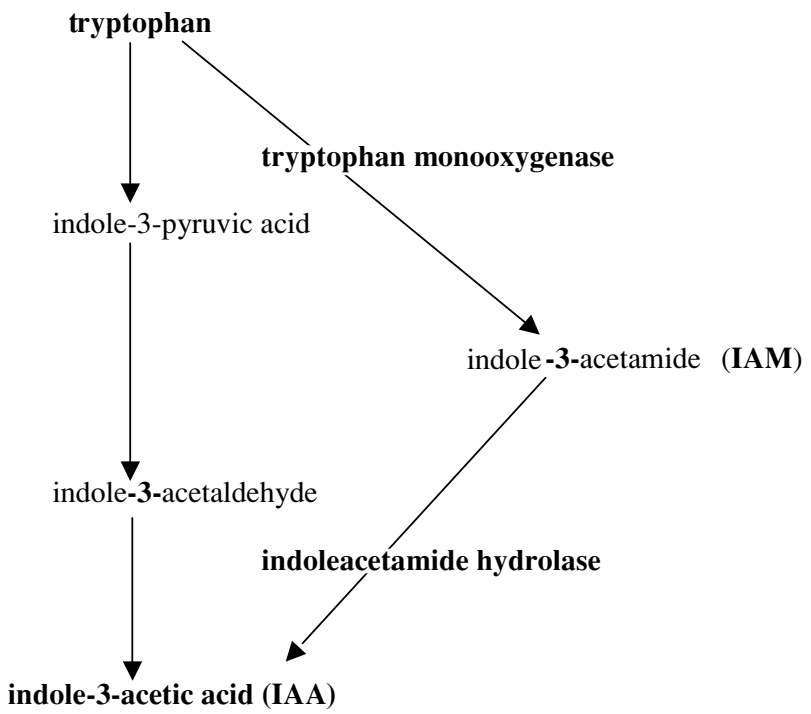

Fig. 1. Biosynthetic pathway of IAA via IAM catalyzed by indoleacetamide hydrolase.

Co., Ltd., Osaka, Japan) was constructed according to the report (Hoson et al. 1992). The 3-D clinostat was controlled by clinostat control system (CL-CS1, Minamide System Engineering Co., Ltd., Osaka, Japan).

Statistical analyses

The significance of differences in each data was determined by Student's t-test for equal valiance.

\section{Results and Discussion}

Growth and development of R12 transformed with iaaH gene under simulated microgravity conditions on a 3-D clinostat

The presence of $i a a H$ gene in genomic DNA of R12 transformants was confirmed by PCR amplification of an internal fragment of $i a A H$ gene. PCR products were verified to have an $i a a H$ gene sequence by Southern hybridization probed iaaH gene (Fig. 2).

Exogenously applied IAM substantially inhibited root growth and extensively promoted the formation of lateral roots in R12 although IAM did not inhibit the root growth of Columbia ecotype (Oka et al. 1999). These results indicate that $\mathrm{ia} H$ gene in $\mathrm{R} 12$ is always expressing and indoleacetamide hydrolase is produced during the growth of R12, resulting in the overproduction of IAA when R12 is grown on the medium containing IAM. The results of previous reports support our considerations. Cauliflower mosaic virus $35 \mathrm{~S}$ promoter driving $\mathrm{ia} \mathrm{aH}$ gene has been well known as a strong promoter that shows no tissuespecificity of gene expression (Odell et al. 1985). It induces high gene expression in all organs of Arabidopsis (Atanassova et al. 1992), in the apical meristem of tobacco (Lepetit et al. 1992) and in floral organs of Arabidopsis (Tsukaya et al. 1993). In addition, IAA applied exogenously has been shown to inhibit root growth and to promote the initiation of lateral root primordia (Torrey 1976, Wightman 


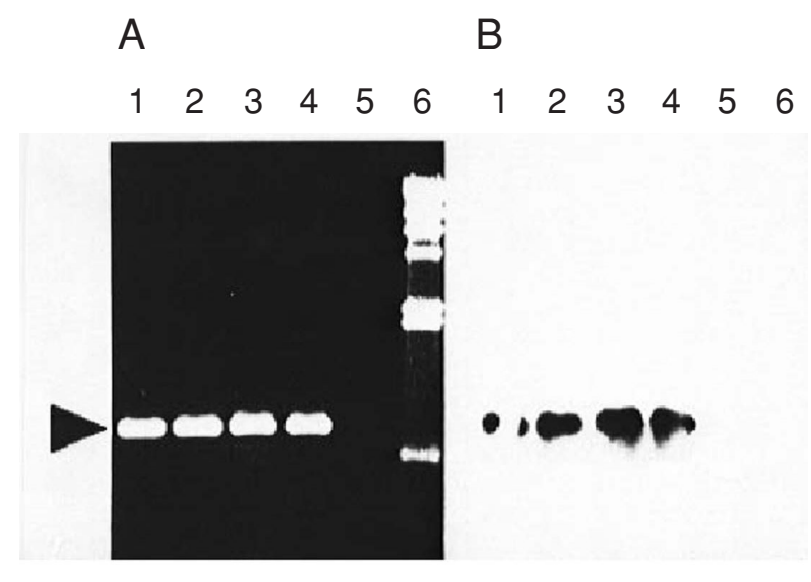

Fig. 2. PCR amplification of iaaH gene in transgenic Arabidopsis (A) and Southern hybridization using $i a a H$ gene probe (B). Lanes 1 to 4: transgenic Arabidopsis, 5: Columbia ecotype, 6: DNA size marker ( $\lambda$ DNA digested by HindIII).

et al. 1980, Blakesley et al. 1991).

Number of rosette leaves was not affected with $i a a H$ gene in the presence or absence of IAM on $1 \mathrm{~g}$ conditions (data not shown). On the contrary, fresh weight of plants (aerial part) was slightly promoted with iaaH gene in the presence of low concentrations $(0.1$ to $1.0 \mu \mathrm{M})$ of IAM (Fig. 3), but not in the presence of relatively high concentration $(10 \mu \mathrm{M})$. The growth promotion of plants in the presence of low concentrations of IAM depended on the significant promotion of flower stalk growth (Fig. 4). Although it is difficult to explain the growth promotion of plants, it might be due to the concentration of endogenous free IAA derived from IAM in the presence of $i a a H$ gene. Relatively high concentration of endogenous IAA in R12 transformants in the presence of IAM has been already reported (Oka et al. 1999).

Simulated microgravity conditions on a 3-D clinostat substantially affected growth and development of Arabidopsis R12 transformants in the presence of IAM except the number of rosette leaves (data not shown). Fresh weight of R12 transformants in the presence of low concentration $(0.1 \mu \mathrm{M})$ of IAM was significantly promoted by simulated microgravity conditions on a 3-D clinostat (Fig. 3), but slightly inhibited in the presence of relative high concentration $(10 \mu \mathrm{M})$. However, growth of flower stalk of transformants in the presence of IAM ( 0.1 to 10 $\mu \mathrm{M})$ was not affected by simulated microgravity conditions on a 3-D clinostat (Fig. 4). As described above, growth promotion of flower stalk of non-transformants (Columbia ecotype) observed in the presence of $1 \mu \mathrm{M}$ IAM was almost equal to that on simulated microgravity conditions on a 3$\mathrm{D}$ clinostat. These results suggest that growth promotion of flower stalk of transformants on simulated microgravity conditions on a 3-D clinostat due to relatively high levels of endogenous IAA concentrations and/or promotion of IAA polar transport activities in the presence or absence of IAM (Fig. 5) describing below. There is a possible explanation that endogenous levels of IAA in R12

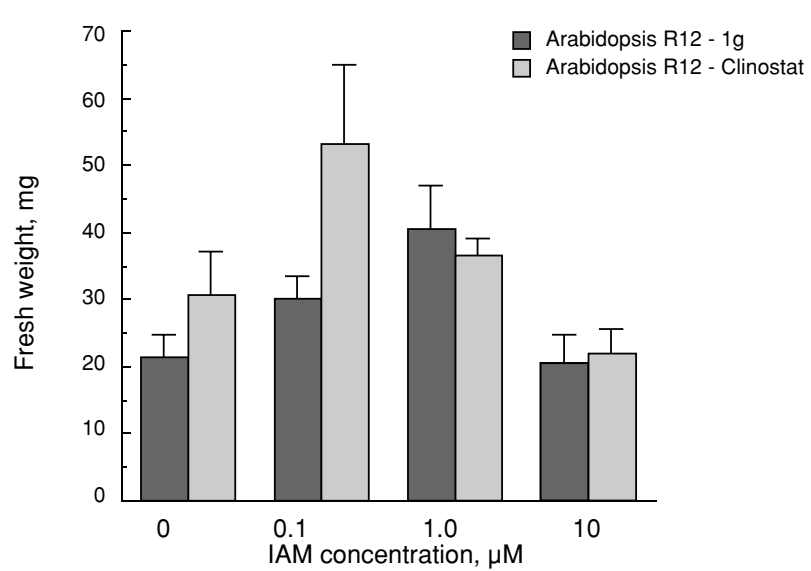

Fig. 3. Effect of simulated microgravity conditions on a 3-D clinostat on the growth (fresh weight of aerial part) of transgenic Arabidopsis in the presence or absence of IAM. Results are expressed as the mean with standard error ( $\mathrm{n}=7$ to 21 ).

transformants in the presence or absence of IAM are enhanced by simulated microgravity conditions on a 3-D clinostat, although weight and hormone content of the microgravity maize seedlings were, with minor exceptions, not statistically different from seedlings grown in normal gravity (Schulze et al. 1992).

Auxin polar transport of iaaH transformants under simulated microgravity conditions on a 3-D clinostat

Activities of auxin polar transport in the segment of flower stalk of R12 transformants were measured using $\left[{ }^{14} \mathrm{C}\right]$ labeled IAA. Auxin polar transport of R12 transformants on $1 \mathrm{~g}$ conditions was significantly promoted in the presence of IAM at concentrations of 1 to $10 \mu \mathrm{M}$ due to relatively high levels of endogenous IAA converted from IAM with iaaH gene product (Fig. 5). On the other hand, simulated microgravity conditions on a 3-D clinostat enhanced activities of auxin polar transport in R12 transformants in the presence or absence of IAM, they being almost equivalent to those of R12 in the presence of IAM

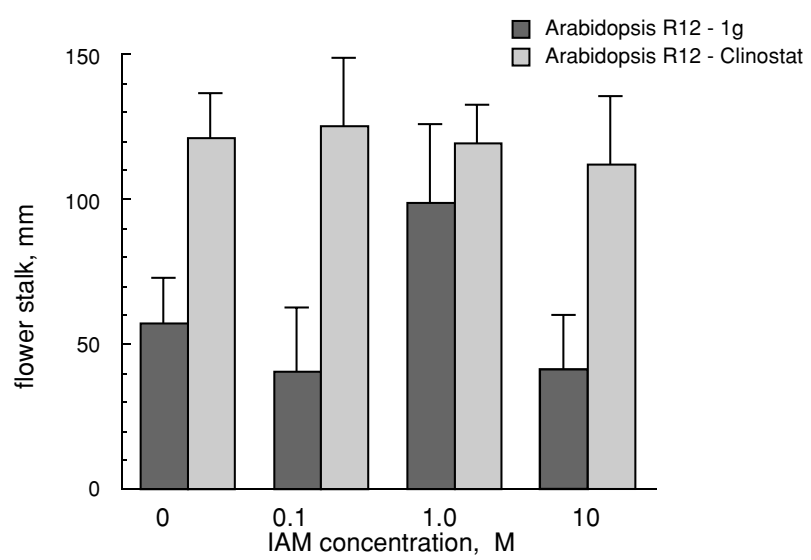

Fig. 4. Effect of simulated microgravity conditions on a 3-D clinostat on the growth of flower stalk of transgenic Arabidopsis in the presence or absence of IAM. Results are expressed as the mean with standard error $(n=7$ to 21$)$. 


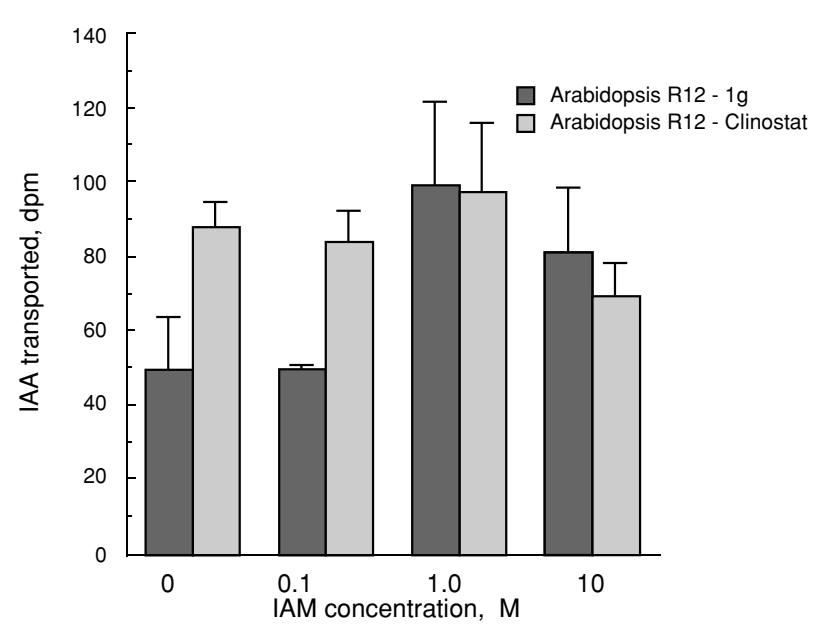

Fig. 5. Effect of simulated microgravity conditions on a 3-D clinostat on IAA polar transport in flower stalk of transgenic Arabidopsis in the presence or absence of IAM. Results are expressed as the mean with standard error ( $\mathrm{n}=7$ to 21 ).

on $1 g$ conditions (Fig. 5). The reason why simulated microgravity conditions promoted auxin polar transport is not clear yet as well as that of growth promotion of flower stalk. It might depend on relatively high levels of endogenous IAA. Extremely high levels of IAA due to $\mathrm{iaaH}$ gene product in $\mathrm{R} 12$ transformants were reduced by metabolizing into its conjugate form (Oka et al. 1999).

Based on the results in this study, transgenic plants may not have an efficient homeostatic mechanism for the control of growth and development, and auxin polar transport activity in microgravity conditions in space.

\section{Acknowledgement}

The authors thank Professor Kiyotaka Okada of Kyoto University and Dr. Robert Masterson of Max-PlanckInstitute for supplying seeds of transformants, and also thank Professor Masamichi Yamashita of Japan Aerospace Exploration Agency (former Institute of Space and Astronautical Science, Japan) for supporting to build the 3-D clinostat system. This work was partially supported by the fund of the Institute of Space and Astronautical Science, Ministry of Education, Science, Sports and Culture of Japan, for Basic Experiments Oriented to Space Station Utilization, and by the fund for Ground Research for Space Utilization promoted by former NASDA and Japan Space Forum.

\section{References}

Atanassova, R., Chaubet, N. and Gigot, C. (1992) A 126bp fragment of a plant histone gene promoter confers preferential expression in meristems of transgenic Arabidopsis. Plant J., 2, 291-300.

Blakesley, D., Weston, G. D. and Hall, J. F. (1991) The role of endogenous auxin in root initiation. Part I. Evidence from studies on auxin application, and analysis of endogenous levels. Plant Growth Regul., 10, 341-353.
Hoson, T., Kamisaka, S., Masuda, Y. and Yamashita, M. (1992) Changes in plant growth processes under microgravity conditions simulated by a three-dimensional clinostat. Bot. Mag. Tokyo, 105, 53-70.

Kawaguchi, M., Fujioka, S., Sakurai, A., Yamaki, Y. T. and Syono, K. (1993) Presence of a pathway for the biosynthesis of auxin via indole-3-acetamide in Trifoliata Orange. Plant Cell Physiol., 34, 121-128.

Kemper, E., Waffenschmidt, S.,Weiler, E. W., Rausch, T. and Schröder, J. (1985) T-DNA coded auxin formation in crown gall cells. Planta, 163, 257-262.

Kosuge, T., Haskett, M. G. and Wilson, E. E. (1966) Microbial synthesis and degradation of indole-3-acetic acid. I. The conversion of L-tryptophan to indole-3-acetamide by an enzyme system from Pseudomonas savastano. J. Biol. Chem., 241, 3738-3744.

Lepetit, M., Ehling, M., Chaubet, N. and Gigot, C. (1992) A plant histone gene promoter can direct both replication-dependent and -independent gene expression in transformants. Mol. Gen. Genet., 231, 276-285.

Morris, R. O. (1986) Genes specifying auxin and cytokinin biosynthesis in phytopathogens. Annu.Rev. Plant Physiol., 37, 509-538.

Odell, J. T., Nagy, F. and Chua, N. -H. (1985) Identification of DNA sequences required for activity of the cauliflower mosaic virus 35 S promoter. Nature, 313, 810-812.

Oka, M., Ueda, J., Miyamoto, K., Yamamoto, R., Hoson, T. and Kamisaka, S. (1995) Effect of simulated microgravity on auxin polar transport in inflorescence axis of Arabidopsis thaliana. Biol. Sci. Space, 9, 331-336.

Oka, M., Miyamoto, K., Okada, K. and Ueda, J. (1999) Auxin polar transport and flower formation in Arabidopsis thaliana transformed with indoleacetamide hydrolase $(\mathrm{iaaH})$ gene. Plant Cell Physiol., 40, 231-237.

Schulzu, A., Jensen, P. J., Desrosiers, M., Buta, J. R. and Bandurski, R. S. (1992) Studies on the growth and indole-3acetic acid and abscisic acid content of Zea mays seedlings grown in microgravity. Plant Physiol., 100, 692-698.

Sekine, M., Ichikawa, T., Kuga, N., Kobayashi, M., Sakurai, A. and Syono, K. (1988) Detection of the IAA biosynthetic pathway from tryptophan via indole-3-acetamide in Bradyrhizobium spp. Plant Cell Physiol., 29, 867-874.

Sitbon, F., Sundberg, B., Olsson, O. and Sandberg, G. (1991) Free and conjugated indoleacetic acid (IAA) contents in transgenic tobacco plants expressing the iaaM and iaaH IAA biosynthesis genes from Agrobacterium tumefaciens. Plant Physiol., 95, 480-485.

Thomashow, L. S., Reeves, S. and Thomashow, M. F. (1984) Crown gall oncogenesis: evidence that a T-DNA gene from the Agrobacterium Ti plasmid pTiA6 encodes an enzyme that catalyzed synthesis of indoleacetic acid. Proc. Natl. Acad. Sci. USA, 81, 5071-5075.

Torrey, J. G. (1976) Root hormones and plant growth. Annu. Rev. Plant Physiol., 27, 435-459.

Tsukaya, H., Takahashi, T., Naito, S. and Komeda, Y. (1993) Floral organ-specific and constitutive expression of an Arabidopsis thaliana heat-shock HSP18.2::GUS fusion gene is retained even after homeotic conversion of flowers by mutation. Mol.Gen.Genet., 237, 26-32. 
Ueda, J., Miyamoto, K., Oka, M., Yamamoto, R., Hoson, T. and Kamisaka, S. (1996) Auxin polar transport in inflorescence axis of Arabidopsis thaliana under simulated microgravity conditions. Space Utilization Res., 13, 23-26 (in Japanese with English abstract).

Ueda, J., Miyamoto, K., Oka, M., Hoson, T. and Kamisaka, S. (1997) Growth and development, and auxin polar transport in higher plants in space. - Experimental design for determination of auxin polar transport. Space Utilization Res., 14, 86-89 (in Japanese with English abstract).

Ueda, J., Miyamoto, K., Fujii, S., Yamamoto, R., Masuda, Y. and Yamashita, M. (1999) Growth and development, and auxin polar transport in higher plants under simulated microgravity conditions. Space Utilization Res., 15, 97-100 (in Japanese with English abstract).

Van Onckelen, H., Rudelsheim, P., Inze, D., Follin, A., Messens, E., Horemans, S., Schell, J., Van Montagu, M. and De Greef, J. (1985) Tobacco plants transformed with the Agrobacterium T-DNA gene 1 contain high amounts of indole-3-acetamide. FEBS Lett., 181, 373-376.

Wightman, F., Schneider, E. A. and Thimann, K. V. (1980) Hormonal factors controlling the initiation and development of lateral roots. II. Effects of exogeneous growth factors on lateral root formation in pea roots. Physiol. Plant, 49, 304314. 